Ольга Ткаченко, к.ф.-м.н.,

(доцент кафедри інформаційних технологій, Державний університет інфраструктури та технологій)

Олександр Ткаченко, к.ф.-м.н.,

(доцент кафедри інженерії програмного забезпечення, Національний авіаційний університет )

Костянтин Ткаченко, к.е.н.,

(стариий викладач кафедри інформаційних технологій, Державний університет інфраструктури та технологій)

\title{
ВИКОРИСТАННЯ ОНТОЛОГІЧНИХ МОДЕЛЕЙ В ЦИФРОВІЗАЦЇ̈ ТРАНСПОРТУ: ПРОБЛЕМИ ТА ПЕРСПЕКТИВИ
}

Розглянуто проблеми та перспективи застосування онтологій у иифровізаиії транспорту. Для вирішення проблем иифровізації транспорту важливе значення мають онтології, формалізовані онтологічні та семантичні мови для забезпечення процесів проектування $i$ експлуатації транспортних систем. Розглянуто світовий досвід по ијифровізаиії транспорту на основі формальних онтологічних моделей, описані онтологї̈, побудовані на базі SysML.

Ключові слова: ициррова економіка, цифровізація транспорту, семантичні моделі, онтологічні моделі, інженерні онтології.

Вступ, аналіз останніх досліджень і постановка проблеми. В наш час інформаційні технології широко використовуються в архітектурі, інженерії та будівництві: складні CADсистеми [1], 3D-моделі будівель і споруд [2] і т. д. Ця методологія стала відома як інформаційне моделювання будівель (BIM, Building Information Modeling) [3].

Розвиток i вдосконалення транспорту потребує, зокрема, збільшення вантажо- та пасажиропотоків, що обумовлює боротьбу за ці потоки між різними видами транспорту i створення нової концепції розвитку транспортних систем, яка грунтується на використанні моделей транспортних об’єктів i процесів. Тому особливо важливим i актуальним $\epsilon$ використання ВIM для узгодженого управління інформацією/знаннями про об'єкти транспортної інфраструктури протягом усього їх життєвого циклу, особливо на етапі експлуатації. Використання ВIM, в тому числі й онтологічного моделювання [3], сприятиме цифровізації транспорту.

Мета і завдання дослідження - визначення та аналіз проблем цифровізації транспорту та шляхів їх вирішення. Інструментарієм досягнення поставленої мети та вирішення поставлених завдань мають стати онтологічні моделі.

Матеріали та методи дослідження. Семантична модель - це модель, в яку включена семантична інформація, що описує зміст іiі конкретних елементів чи зразків. Наприклад, в $[4,5]$, моделі IFC (Industry Foundation Classes) [6] є семантичними. На транспорті використовують різні моделі, зокрема моделі з великою кількістю даних, що обумовлює необхідність управління розподіленими даними на базі деякої моделі, наприклад, ВІМ (див. рис. 1 [7]).

DOI:10.32703/2617-9040-2020-35-12

Збірник наукових праць ДУІТ. Серія «Транспортні системи і технології», 2020. Вип. 35 
За допомогою семантичних веб-технологій інформація моделі IFC на основі EXPRESS перетворюється в семантично розширену модель об'єктів і процесів, яку можна описати онтологічною мовою OWL [8]. IfcOWL (версія OWL моделі IFC) використовує семантичні вебтехнології для моделей BIM. Перевагами семантичних веб-технологій та IFC OWL є: можливість зв’язувати різні типи даних і додатків однієї й тієї ж концепції з елементами, запитами на дані, публікацією даних, обгрунтуваннями і специфікаціями даних.

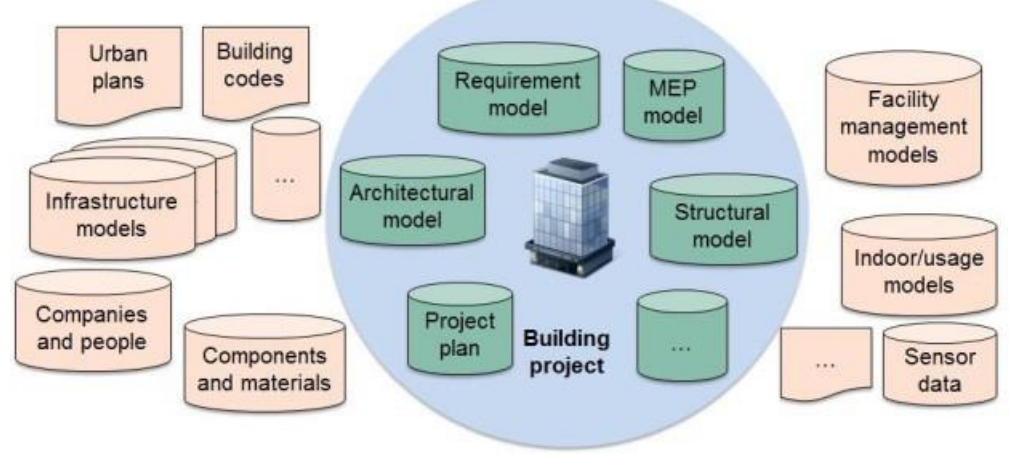

Рис. 1. Управління розподіленими даними у ВIM

Рис. 2 [7] ілюструє різницю в підходах до управління даними. Підхід «Old School» заснований на технологіях STEP, XML, а онтологічний підхід «New School» є більш гнучким i динамічним і грунтується на семантичній мережі.

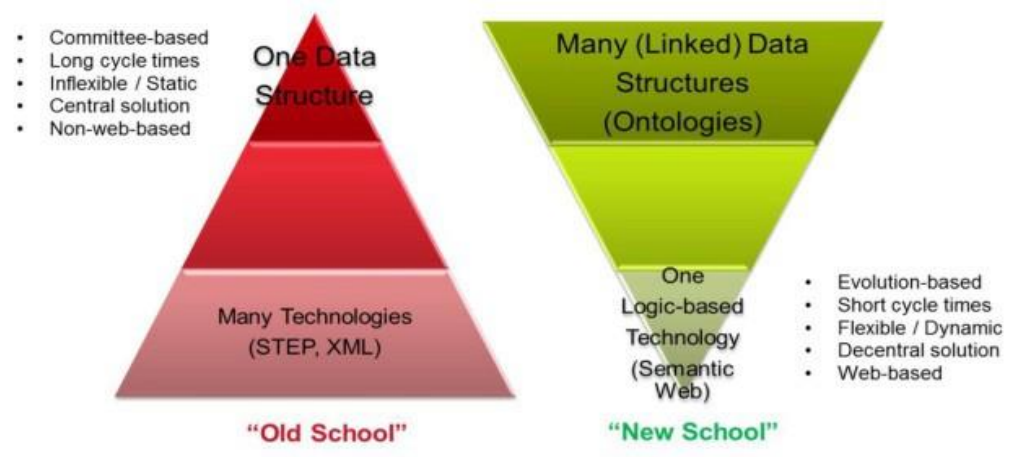

Рис. 2. Зв'язок між традиційними і онтологічними методами

Враховуючи особливості різних профілів OWL, існують різні варіанти побудови відносин з IFC. Онтологія IFC OWL використовується як для розв'язання задач так званого «універсального» проектування (3 максимально можливою інформацією), так i для «унікального» («індивідуального») проектування при вирішенні конкретних завдань у вигляді спеціальних прикладних додатків.

Для стандартизації правил трансформації розвиток IFC OWL існує спеціальний орган стандартизації. BuildingSMART [8], що відповідає за створення і підтримання онтології IFC OWL в проектах, які пов'язані з розширенням BIM на весь життєвий цикл, OWL розглядається i застосовується як інтегратор всіх необхідних онтологій і єдиний механізм створення Web-додатків.

EULYNX [9].використовує формальні онтологічні методи в багатьох галузях, але не дуже поширений серед менеджерів транспортної інфраструктури. Впровадження розподіленої системи безпеки на транспорті $є$ важливим та інноваційним.

Онтології цифровізації транспорту. Дослідження щодо використання онтологій на залізничному транспорті у Великобританії показали, що: «... ефективність інформаційних систем (IC) в галузі гальмується застарілими системами, що не можуть використовувати нові технології і заохочувати користувачів розробляти системи для подолання існуючих проблем» [5].

Збірник наукових праць ДУІТ. Серія «Транспортні системи і технології», 2020. Вип. 35 
Побудована на основі онтологій транспортна система (відповідна ій IC) є комбінацію взаємодіючих елементів (продуктів, процесів, користувачів, властивостей, послуг, функцій тощо), підсистем або комплексів підсистем, які виконують конкретні завдання. Наприклад, проект повторної сигналізації на транспорті ERTMS є прикладом розвитку системи безпеки, що реалізована згідно з «V-моделлю» [10], яка використовується і в EULYNX [9].

Онтологія транспорту має загальні частини, зокрема: транспортна інфраструктура, рухомі засоби, кадровий персонал тощо. Розвиток цифровізації транспорту все більше залучає інженерні, програмні та ВIM-онтології. Можливість працювати 3 обмеженим набором формалізованих понять і великим набором формалізованих відносин між ними дозволяє накопичувати знання та використовувати їх на практиці для отримання кращих результатів.

Підсистеми моделюються в онтологіях, використовуючи різні обчислювальні моделі: кінцеві автомати, системи дискретних подій, моделі потоків даних, сигнальні моделі, семантичні мережі тощо. Взаємодія трьох обчислювальних моделей у визначених точках онтологічної моделі подана на рис. 3 [10].

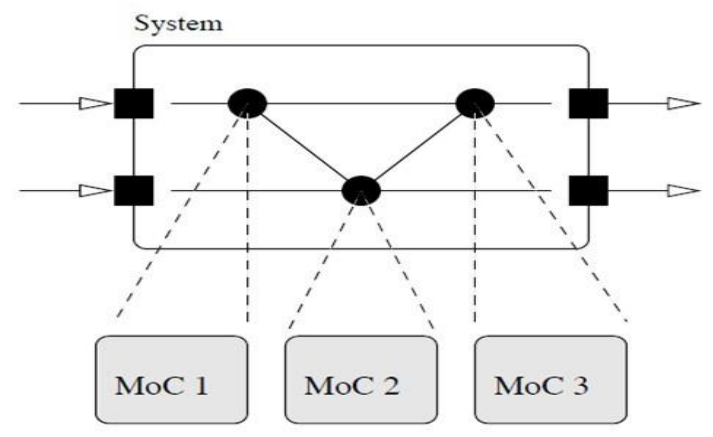

\section{Рис. 3. Взаємодія обчислювальних моделей у визначених точках онтологічної моделі}

Онтології інфраструктур транспорту. 3 розвитком онтологій 3'явилася можливість створення систем управління знаннями. Наприклад, онтологічна ВIM надає унікальне джерело інформації, бо генерує i управляє даними, створеними протягом життєвого циклу інфраструктурної транспортної будівлі. Онтології інфраструктур транспорту тісно пов'язані 3 IFC buildibgSmart та їх розширеннями. Стандарт інфраструктури IFC Rail [6], наприклад, не включає залізничні мости i тунелі (це в онтології окремий домен), вокзали і депо (за класифікацією buildibgSmart це домен інфраструктурної транспортної будівлі).

Сучасні симуляційні системи інфраструктурних транспортних будівель використовують знання про будівлю та її домени. Це пояснює необхідність формальних інформаційних моделей і структур знань, які застосовуються у базах знань щодо інфраструктурних транспортних будівель і споруд.

Сучасні стратегії управління інфраструктурою транспорту часто приймають рішення лише на основі кількісних (числових) показників та їх значень, ігноруючи семантичні знання щодо інфраструктурних об'єктів та багато важливої інформації (наприклад, інформацію про пасажиропотік, геометрію будівлі для енергопостачання вокзалу).

Технології Semantic Web [8] діють як абстракції в поданні семантичних знань щодо інфраструктурних транспортних об'єктів (будівель). Тут онтології $\epsilon$ частиною семантичних моделей, які представляють концепції кожного домена, разом 3 їх властивостями та взаємозв'язками. Правила, засновані на висновках (результатах процедури виведення нових знань), надають механізми для отримання нових знань на основі тих, що зберігаються в онтологіях.

Інженерні онтології транспорту на основі моделей (MBSE) [11] передбачають створення і використання моделей доменів як засобу обміну інформацією між інженерами, сприяють підвищенню ймовірності «отримати правильне рішення», бо вся інформація підключена до єдиної моделі даних [5, 6]. 
Організація інженерних процесів в MBSE сприяє:

1. Виявленню проблем цифровізації транспорту.

2. Побудові моделі прийняття рішень щодо транспорту та його цифровізації.

3. Використанню SysML [4, 5] як інформаційно-керуючої структури в специфічних інженерних доменах.

4. Скороченню часу розробки системи за рахунок багаторівневої онтологічної моделі.

Перевагами онтологій, що побудовані на базі SysML, $\epsilon$ :

- візуалізація опису транспортної системи для більш кращого їі розуміння та інтерпретації;

- допомога в управлінні транспортною системою через відображення взаємозв'язків між різними компонентами та процесами на всіх етапах життєвого циклу системи (від збору вимог i дизайну до тестування і перевірки).

Система блокування $є$ важливою частиною сигналізації на транспорті (зокрема, на залізниці вона забезпечує безпечний рух потягів). Система блокування породжує проблеми для інженерних онтологій (наприклад, через складний характер інженерного проектування процесів блокування). RailML [12] усуває багато з цих проблем (зокрема, взаємоблокування) та автоматизує розробку протоколів тестування. Використання RailML при інженерному проектуванні сприяє зниженню витрат, наприклад, у Siemens залежно від комплексу проектів собівартість знижувалася на 21\%-35\%. RailML потребує значних обсягів даних, тому цей підхід на складних проектах працює не так ефективно, як на простих [12].

Метою застосування онтологічних моделей є створення цифрового інструментарію для поліпшення основних показників транспорту. В цьому напрямі працює Shift2Rail [13] європейська ініціатива з пошуку досліджень, інновацій та управлінських рішень на транспорті (зокрема, залізничному), прискорюючи інтеграцію передових технологій в інноваційні рішення для залізничних продуктів. Shift2Rail підвищує конкурентоспроможність європейської залізничної системи, відповідаючи потребам ЄС і скорочуючи витрати на життєвий цикл, та спрямована на збільшення пропускної здатності європейської залізничної системи, підвищення iii надійності та якості обслуговування. У Shift2Rail значна увага приділяється EULYNX, що надає стандартні специфікації для транспорту.

Концепція EULYNX полягає в тому, що модель $є$ основним контейнером вимог. Рішеннями EULYNX, зокрема, $€$ :

Система виявлення потягів (TDS) для визначення зайнятості ділянки залізниці, щоб забезпечити безпеку руху потягів. Методами TDS є:

- Трек ланцюга, що використовується на залізницях Нідерландів. Коли потяг входить на ділянку, він замикає струм в рейці, знеструмлюючи реле і повідомляючи, що ділянка зайнята.

- Axle Counter використовує пристрої, розташовані на початку і в кінці кожної ділянки для визначення напрямку руху потягу.

Блокування в системі сигналізаиї - система запобігання конфліктам під час руху потягів. Блокування пов'язане 3 системами виявлення потягів на маршруті, сигналами та іншими підсистемами.

EULYNX розроблений на базі DB Netz AG NeuPro [14]. NeuPro забезпечує створення стандартизованої специфікації інтерфейсу i в Німеччині до NeuPro додається більше функціональних можливостей [8]. Для кожної підсистеми збираються всі функції, що пов'язані з інтерфейсом. Після їх схвалення створюються специфікації вимог, які містять моделі SysML $[4,5]$, які враховують вимоги користувачів і вимоги до системи. Моделювання в EULYNX як процес MBSE використовується для:

- опису придатних для тестування вимог до підсистем;

- підтримки досягнення узгодженості, недвозначності і повноти вимог;

- раннього тестування і обробки помилок функціональних вимог;

- автоматичного генерування тестів зі специфікації вимог.

Моделювання відіграє важливу роль в проекті, тому в EULYNX сформовано кластер Моделювання і Тестування, який відповідає за створення документів процесу моделювання. Для кожної підсистеми зі списків функцій створюється специфікація вимог та такі типи документів: визначення інтерфейсу для кожного типу інтерфейсу, специфікації інтерфейсу і специфікації вимог.

Збірник наукових праць ДУІТ. Серія «Транспортні системи і технології», 2020. Вип. 35 
Специфікація інтерфейсу EULYNX визначає прикладний рівень (PDI) 3 інтерфейсу протоколу. Зв'язок між підсистемою блокування та іншими підсистемами представлено у вигляді команд/ повідомлень. Цей документ містить технічні вимоги, опис кожної команди/ повідомлення, що відправляється через інтерфейс між підсистемою блокування і конкретною підсистемою. EULYNX визначає та описує: пов'язані підсистеми; обмін інформацією між підсистемами через інтерфейс; поведінку підсистем, що відносяться до інтерфейсу; стан підсистем та їх інтерфейсів; набір дій (прецедентів), включаючи ініціалізацію, роботу і управління, за допомогою яких підсистеми взаємодіють між собою; набір сценаріїв - послідовності дій, які призводять до успіху чи невдачі.

DB Netz відіграє важливу роль в EULYNX, маючи перевагою легку адаптацію до процесу EULYNX, змінюючи свій робочий процес відповідно до EULYNX.

В рамках кластера Моделювання і Тестування формується рішення про те, які моделі повинні створюватися, відображаються зміни в онтологічних моделях тощо. Спочатку створюються моделі та отримується зворотний зв'язок від замовників моделі після завершення моделювання для подальшої модифікації моделі. Аналіз та тестування моделі (моделей) відбувається в кластері.

Встановлені в EULYNX довгострокові стабільні інтерфейси сприяють оновленню та модифікації моделей на рівні відповідних модулів. Онтологічне моделювання стає базою цифровізації транспорту (в тому числі й залізниці), яка сприятиме кращому захисту інвестицій та інноваціям. Онтологічна модель для інтеграції ВIM та даних $є$ основою цифровізації транспорту.

Розробники моделей мають вирішувати проблеми прогнозування затримок транспортних засобів та перевезень, обслуговування інфраструктури транспортної системи (зокрема, залізничної), планування розкладів тощо. Існує багато алгоритмів, моделей та технологій вирішення цих проблем, наприклад:

- нейромережеві технології сприяють передбаченню збоїв у транспортній мережі 3 точністю 97\%;

- методи машинного навчання сприяють цифровізації та інтелектуалізації процесів обслуговування на транспорті;

- алгоритми генерації та різні мережеві моделі сприяють вирішенню проблем оптимізації розкладу;

- мови моделювання і мережі Петрі сприяють оптимізації систем управління потягом; -

байєсовські мережеві моделі поліпшують стратегії обслуговування транспортної інфраструктури (в тому числі й залізничної).

Рішення щодо цифровізації транспорту є платформами [15], наприклад:

- Xerox (MAР) використовує аналітику даних для управління i прогнозування пасажиропотоків.

- SPATIOWL використовує технологію штучного інтелекту для прогнозування затримки потягів в японській залізничній мережі.

- MDS Siemens використовує методи машинного навчання для прогнозування затримок рухомого складу та підвищення пунктуальності.

- Hacon (TPS) використовує алгоритми створення і адаптації оптимальних графіків потягів.

- Qognify використовує прогнозування тенденцій швидкого поширення інформації для управління інцидентами.

Висновки. Онтологічні моделі допомагають побудувати ефективну цифрову кооперацію і забезпечити цифрову безперервність через онтологію стандартів. EULYNX використовується при необхідності розробки стандартів цифровізованого транспорту.

Онтологічні моделі охоплюють процеси, які відбуваються на транспорті, та відіграють все більш вирішальну роль. Такі моделі є основою цифровізації транспорту. За допомогою онтологічних моделей можна, зокрема, надавати та візуалізовувати детальну інформацію

Збірник наукових праць ДУІТ. Серія «Транспортні системи і технології», 2020. Вип. 35 
команди/повідомлення, якими обмінюються підсистеми; час та умови ініціалізації підсистем; стан підсистем; проблеми і помилки функціонування транспортної системи чи окремих ії підсистем.

\section{ЛIТЕРАТУРА}

1. Top 10 Best CAD Software For All Levels. URL: https://www.3dnatives.com/en/top10-cad-software-180320194/ (дата звернення 29.04.2020).

2. Створення і візуалізація $3 \mathrm{~d}$ моделі місцевості, створення тривимірних моделей будівель та промислових об'єктів. URL: https://mirnychyj.com.ua/lazerne-3d-skanuvannya/stvorennya-i-vizualizaciya-3d-modeli-misc/ (дата звернення 27.03.2020).

3. BuildingSMART open BIM. URL: https://www.tekla.com/ru/content/buildingsmart-open-bim_(дата звернення 29.03.2020).

4. Kupriyanovsky V., Pokusaev O., Volokitin Y., Namiot D., Petrunina I., Zazhigalkin A. Formalized ontologies and services for high-speed and digital railways //International Journal of Open Information Technologies, 2018. Vol. 6. № 6. P. 69-86.

5. Delgoshaei P. Semantic models and reasoning for building system operations: focus on knowledge-based control. Maryland College Park, USA, 2017.

6. IFC Rail - The International Standard Progress Report. URL: https://www.bim-events.de/ifc-rail-the-internationalstandard-progress-report/ (дата звернення 03.04.2020).

7. M.H. van de Riet. Semantic model enrichment for bim-enabled risk-based operation and maintenance. A case study approach with Industry Foundation Classes. Eindhoven University of Technology, Arcadis Nederland, 2016. 216 p.

8. Лаврищева, Е.М., Карпов, Л.Е., Томилин, А.Н. Семантические ресурсы для разработки онтологии научной и инженерной предметных областей. URL: https://keldysh.ru/abrau/2016/16.pdf (дата звернення 29.04.2020).

9. EULYNX: a route to standardization. Global Railway Review. URL: https://www.eulynx.eu (дата звернення 29.03.2020).

10. M. Jansen van Galen. Energy Efficient Train Control in the Netherlands Analysis of effects on a large scale network with distributed delays. Civil Engineering and Management specialization Transport Engineering and Management University of Twente. 2016.

11. MBSE - Systems Engineering Yhinking Wiki. URL: http://sewiki.ru/MBSE (дата звернення 07.04.2020).

12. Bosschaart Mark. Lean Engineering Design of Rail Interlocking Systems with RailML //Thesis Report Master TIL. Siemens NL \& Delft University of Technology ( October 1th 2016), Germany. 2016.

13. Shift2Rail: driving innovation on railways. URL: https://ec.europa.eu/research/press/jti/factsheet_s2r-web.pdf (дата звернення 08.04.2020).

14. Machbarkeitsstudie zum Projekt Zukunft Bahn (ETCS/NeuPro). URL: https:// www.bmvi.de/SharedDocs/DE/Anlage/E/machbarkeitsstudie-zukunft-bahn.pdf?_blob=publicationFile (дата звернення 08.04.2020).

15. Data architectures and advanced analytics for transport operations modelling (S276). RAIL SAFETY AND STANDARDS BOARD LTD, 2017.

\section{REFERENCES}

1. Top 10 Best CAD Software For All Levels. (2020). Retrieved from https://www.3dnatives.com/en/top10-cadsoftware-180320194/ (Accessed 29 April 2020). (in English).

2. Stvorennya i vizualizatsiya 3d modeli mistsevosti, stvorennya tryvymirnykh modeley budivel' ta promyslovykh ob"yektiv [Creating and visualizing a 3D terrain model, creating 3D models of buildings and industrial sites]. (2020). Retrieved from https://mirnychyj.com.ua/lazerne-3d-skanuvannya/stvorennya-i-vizualizaciya-3d-modeli-misc/ (Accessed 27 March 2020).

3. BuildingSMART open BIM. (2020). Retrieved from https://www.tekla.com/ru/content/buildingsmart-open-bim (Accessed 29 March 2020). (in English).

4. Kupriyanovsky V., Pokusaev O., Volokitin Y., Namiot D., Petrunina I., Zazhigalkin A. (2018). Formalized ontologies and services for high-speed and digital railways. International Journal of Open Information Technologies, 6, № 6, 69-86. (in English).

5. Delgoshaei P. (2017). Semantic models and reasoning for building system operations: focus on knowledge-based control. Maryland College Park, USA. (in English).

6. IFC Rail - The International Standard Progress Report. (2020). Retrieved from https://www.bim-events.de/ifcrailthe-international-standard-progress-report/ (Accessed 03 April 2020). (in English).

7. M.H. van de Riet. (2016). Semantic model enrichment for bim-enabled risk-based operation and maintenance. A case study approach with Industry Foundation Classes. Eindhoven University of Technology, Arcadis Nederland. 216 p. (in English).

8. Lavrishcheva, Ye.M., Karpov, L.Ye., Tomilin, A.N. (2016). Semanticheskiye resursy dlya razrabotki ontologii

Збірник наукових праць ДУІТ. Серія «Транспортні системи і технологї̈, 2020. Вип. 35 
nauchnoy $i$ inzhenernoy predmetnykh oblastey. [Semantic resources for the development of the ontology of scientific and engineering subject areas]. Retrieved from https://keldysh.ru/abrau/2016/16.pdf (Accessed 29 April 2020).

9. EULYNX: a route to standardization. Global Railway Review. (2020). Retrieved from https://www.eulynx.eu (Accessed 29 March 2020). (in English).

10. M. Jansen van Galen. (2016). Energy Efficient Train Control in the Netherlands Analysis of effects on a large scale network with distributed delays. Civil Engineering and Management specialization Transport Engineering and Management University of Twente. (in English).

11. MBSE - Systems Engineering Yhinking Wiki. (2020). Retrieved from http://sewiki.ru/MBSE (Accessed 07 April 2020). (in English).

12. Bosschaart Mark. (2016). Lean Engineering Design of Rail Interlocking Systems with RailML. Thesis Report Master TIL. Siemens NL \& Delft University of Technology ( October 1th 2016), Germany. (in English).

13. Shift2Rail: driving innovation on railways. (2020). Retrieved from https://ec.europa.eu/research/press/jti/factsheet_s2r-web.pdf (Accessed 08 April 2020). (in English).

14. Machbarkeitsstudie zum Projekt Zukunft Bahn (ETCS/NeuPro). (2020). Retrieved from https://www.bmvi.de/shareddocs/de/Anlage/E/machbarkeitsstudie-zukunft-bahn.pdf?__blob=publicationFile (Accessed 08 April 2020). (in German).

15. Data architectures and advanced analytics for transport operations modelling (S276). (2017). RAIL SAFETY AND STANDARDS BOARD LTD. (in English).

Ольга Ткаченко, к.ф.--м.н.,

(доцент кафедры информационных технологий, Государственный университет инфраструктуры и технологий)

Александр Ткаченко, к.ф.-м.н.,

(доцент кафедры инженерии программного обеспечения, Национальный авиационный университет)

Константин Ткаченко, к.э.н.,

(стариий преподаватель кафедры информационных технологий, Государственный университет инфраструктуры и технологий)

\section{ИСПОЛЬЗОВАНИЕ ОНТОЛОГИЧЕСКИХ МОДЕЛЕЙ В ЦИФРОВИЗАЦИИ ТРАНСПОРТА: ПРОБЛЕМЫ И ПЕРСПЕКТИВЫ}

Рассмотрены проблемы и перспективы применения онтологий в циифровизации транспорта. Для решения проблем иифровизации транспорта важное значение имеют онтологии, формализованные онтологические и семантические языки для обеспечения прочессов проектирования и эксплуатаџии транспортных систем. Рассмотрен мировой опыт по ичифровизации транспорта на основе формальных онтологических моделей, описань онтологии, построенные на базе SysML.

Ключевые слова: иифровая экономика, иифровизачия транспорта, семантические модели, онтологические модели, инженерные онтологии.

Olha Tkachenko, Ph.D. in Physical and Mathematical Sciences,

(Associate Professor, Department of Information Technologies, State University of Infrastructure and Technologies)

Oleksandr Tkachenko, Ph.D. in Physical and Mathematical Sciences,

(Associate Professor, Department of Software Engineering, National Aviation University)

Kostiantyn Tkachenko, Ph.D. in Economics,

(Senior Lecturer, Department of Information Technologies, State University of Infrastructure and Technologies)

\section{USE OF ONTOLOGICAL MODELS IN DIGITALIZATION OF TRANSPORT: PROBLEMS AND PROSPECTS}

The article deals with current problems and prospects of digitalization of transport (transport systems). It is suggested to use modeling of processes and objects of transport systems to solve the

Збірник наукових праць ДУІТ. Серія «Транспортні системи і технології», 2020. Вип. 35 
problems under consideration. Ontology models are considered as models used for the digitization of transport. The article deals with the problems and prospects of using ontologies in the digitization of transport (transport systems, in particular rail systems and its infrastructure: buildings, bridges, etc.). To solve the problems of digitization of transport, ontologies, formalized ontological and semantic languages are essential for ensuring the design and operation of transport systems. Ontological models embrace the processes that take place in transport and play an increasingly crucial role. The article discusses, in particular, how ontological models can provide and visualize detailed information about commands (control messages) exchanged by subsystems of transport systems. The article examines the global experience in digitalisation of transport based on the use of formal ontological models, describes ontologies built on SysML, which are common in transport security systems (in particular, for various types of rail signaling systems).

Keywords: digital economy, transport digitalization, semantic models, ontological models, engineering ontologies. 